\title{
Hippocampal Glial Degenerative Potentials of Mefloquine and Artequin in Adult Wistar Rats
}

\author{
Nsikan-Abasi B. Udoh,, ${ }^{1}$ Theresa B. Ekanem, ${ }^{2}$ Moses B. Ekong, \\ Aniekan I. Peter, ${ }^{1}$ and Amabe O. Akpantah ${ }^{2}$ \\ ${ }^{1}$ Department of Anatomy, Faculty of Basic Medical Sciences, University of Uyo, PMB 1017, Uyo, Nigeria \\ ${ }^{2}$ Department of Anatomy, Faculty of Basic Medical Sciences, University of Calabar, PMB 1115, Calabar, Nigeria \\ Correspondence should be addressed to Moses B. Ekong; mbe_flashpoint@yahoo.com
}

Received 19 December 2013; Revised 3 February 2014; Accepted 17 February 2014; Published 19 March 2014

Academic Editor: Fabio Pilato

Copyright (C) 2014 Nsikan-Abasi B. Udoh et al. This is an open access article distributed under the Creative Commons Attribution License, which permits unrestricted use, distribution, and reproduction in any medium, provided the original work is properly cited.

\begin{abstract}
Mefloquine and Artequin are two effective antimalarial drugs currently in use in the treatment of uncomplicated malaria. This study was to investigate the hippocampal glial degenerative potentials of these drugs in adult Wistar rats. Forty-nine adult Wistar rats weighing $200 \mathrm{~g}$ were divided into groups 1-7. Group 1 served as the control that received distilled water, while groups 2-7 received oral doses of $0.86 / 1.07 \mathrm{mg} / \mathrm{kg}, 1.71 / 2.14 \mathrm{mg} / \mathrm{kg}$, and $3.24 / 4.28 \mathrm{mg} / \mathrm{kg}$ of Artequin and $1.07 \mathrm{mg} / \mathrm{kg}, 2.14 \mathrm{mg} / \mathrm{kg}$, and $4.28 \mathrm{mg} / \mathrm{kg}$ of Mefloquine. The treatment lasted for three days, and on day 4 the animals were sacrificed. Their hippocampi were preserved in neutral formal saline and processed by silver impregnation method. The histomorphology of the hippocampal sections of rats in the groups treated with $2.14 \mathrm{mg} / \mathrm{kg}$ and $4.28 \mathrm{mg} / \mathrm{kg}$ of Mefloquine and $0.86 / 1.07 \mathrm{mg} / \mathrm{kg}, 1.71 / 2.14 \mathrm{mg} / \mathrm{kg}$, and $3.24 / 4.28 \mathrm{mg} / \mathrm{kg}$ of Artequin showed large and dense populations of astrocytes and astrocytes' processes, with either loss or reduction in the population of oligodendrocytes. There was also loss in the population of pyramidal neurons all compared with the control group. In conclusion, Mefloquine and Artequin administration induced dose-dependent reactive astrocytes and astrocytes' processes formation in the hippocampus. This may impair the uptake of neurotransmitter and alter neuronal environment thus altering the hippocampal function.
\end{abstract}

\section{Introduction}

Malaria is one of the tropical diseases caused by the Plasmodium species, falciparum, vivax, and malaria [1]. Despite efforts to control or completely eradicate the disease, malaria continues to be a major cause of human morbidity in the tropics particularly in Southeast Asia and Sub-Saharan Africa with a worldwide prevalence estimated to be in the order of 300-500 clinical cases each year [2].

The treatment of Plasmodium falciparum malaria in Africa is increasingly difficult as resistance to cheap efficient antimalarial drugs such as chloroquine now poses an increasing threat [3]. This is because the emergence of resistance to the malarial parasites is bound to have high impacts on mortality in many African regions [4]. It was as a result of the reported cases of drug resistance that the World Health Organization recommended the introduction of the combination of drugs to replace the single therapeutic drug treatment against Plasmodium falciparum malaria. The use of drug combinations containing the peroxide antimalaria Artemisia which is derived from the herb Artemisia annua was recommended. This combination known as Artemisinin Based Combination Therapy (ACT) provided the solution to the problem of drug resistance $[5,6]$.

Two highly potent ACT partner drugs, artesunate and mefloquine, are the active ingredients of Artequin coblister as well as the fixed dose combination of Artequin pediatric stick pack. Mefloquine is a 4-quinoline methanol blood schizonticide with a long acting half-life [2], while artesunate is a sesquiterpene lactones with a unique endoperoxide bond, usually water soluble, semisynthetic, and a derivative of the Chinese medicinal herb qinghua $[7,8]$. Though Artemisinin derivatives have little or no neurological effect in humans [9], there has been poor documentation on their morphological 
TABLE 1: Dosages of the drugs administered to the rats for three days.

\begin{tabular}{lccc}
\hline Groups $(n=7)$ & Drugs & Average weights & Dosages/day \\
\hline 1 (Control) & Distilled water & 200 & - \\
2 & ATQ (LD eqv.) & 200 & $0.86 / 1.07 \mathrm{mg} / \mathrm{kg}$ \\
3 & ATQ (TD eqv.) & 200 & $1.71 / 2.14 \mathrm{mg} / \mathrm{kg}$ \\
4 & ATQ (HD eqv.) & 200 & $3.42 / 4.28 \mathrm{mg} / \mathrm{kg}$ \\
5 & MQ (LD eqv.) & 200 & $1.07 \mathrm{mg} / \mathrm{kg}$ \\
6 & MQ (TD eqv.) & 200 & $2.14 \mathrm{mg} / \mathrm{kg}$ \\
7 & MQ (HD eqv.) & 200 & $4.28 \mathrm{mg} / \mathrm{kg}$ \\
\hline
\end{tabular}

ATQ: Artequin; MQ: Mefloquine; LD eqv.: low dose equivalent; TD eqv.: therapeutic dose equivalent; HD eqv.: high dose equivalent.

activity, as well as that of Artequin $[2,10]$. However, it has also been shown that antimalarial drugs cause damages to certain organs of the body thus influencing their activities [2].

The hippocampus has been reportedly affected by these drug treatments [11]. This brain area is part of the limbic system structure that is particularly involved in memory, connecting emotions and senses such as smell and sound to memories. As Mefloquine is reported with adverse effects, its presence in Artequin may also indicate a possibility of danger to the hippocampus [11]. Therefore in Africa, where indiscriminate use of drugs sometimes at dosages above the therapeutic dose is the order of the day, it is pertinent to study the effects of these drugs on the structure of the brain to ascertain its safety. Thus, this study aimed at determining the hippocampal glial degenerative potentials of the two drugs, Mefloquine and Artequin, in adult Wistar rats.

\section{Material and Methods}

Forty-nine adult Wistar rats weighing an average of $200 \mathrm{~g}$ were obtained from and kept in the Animal House of the Faculty of Basic Medical Sciences, University of Uyo, Uyo, Nigeria. The room temperature was maintained at $26-28^{\circ} \mathrm{C}$. The animals were allowed access to Pfizer grower mash feed and water ad libitum and were maintained in compliance with the National Institute of Health of the US guidelines for animal research. The approval for animal study and experiment was obtained from the Institutions Ethics Committee.

Mefloquine and Artequin (Mepha Pharmaceutical Limited, Asch-Basal, Switzerland) were purchased from the University of Uyo Pharmacy, Uyo, Nigeria. Each tablet of the drugs, Mefloquine $(750 \mathrm{mg} / \mathrm{kg})$ and Artequin $(600 / 750 \mathrm{mg} / \mathrm{kg}$, coblister tablet), was dissolved in $100 \mathrm{~mL}$ of distilled water. The animals were divided into group one which was the control and six treatment groups (groups 1-7) as shown in Table 1, as reported by Ekanem et al. [11]. The drug suspensions were administered to the animals orally, with the aid of orogastric tubes for three days, according to their body weights.

The animals were sacrificed on day 4 after chloroform anesthetizing. Each of their skulls was dissected and the whole brain was removed and preserved in neutral formal saline for seven days. Each of the hippocampi was dissected out and was routinely processed and stained using the silver impregnation method by Sano et al. [12] modified for paraffin-embedded tissues. The slides were studied, the images of the sections were captured, and photomicrographs were made.

\section{Results}

Silver impregnation of the hippocampal section of control rats showed normal pyramidal neurons, astrocytes, oligodendrocytes, and astrocyte's processes (Figure 1(a)). Section of hippocampus of rats treated with $0.86 / 1.07 \mathrm{mg} / \mathrm{kg}$ of Artequin showed few populations of pyramidal shaped neurons with less visible astrocytes' processes, as well as less impregnated oligodendrocytes compared with control (Figure 1(b)).

The section of the hippocampus of rats treated with $1.71 / 2.14 \mathrm{mg} / \mathrm{kg}$ of Artequin showed mostly prominent astrocytes' processes with less visible pyramidal neurons and glia compared to the control group (Figure 1(c)), while the section of the hippocampus of rats treated with $3.42 / 4.28 \mathrm{mg} / \mathrm{kg}$ of Artequin showed less visible neurons and astrocytes' processes compared to the control group (Figure 1(d)).

The section of the hippocampus of rats treated with $1.07 \mathrm{mg} / \mathrm{kg}$ of mefloquine showed less population density of pyramidal cell neurons with increased population of astrocytes and astrocytic processes compared to the control group (Figure 2(b)). The section of the hippocampus of rats treated with $2.14 \mathrm{mg} / \mathrm{kg}$ of Mefloquine showed increased population of astrocytes with less population of pyramidal neurons in the pyramidal cell layer compared to the control group (Figure 2(c)), while the section of the hippocampus of rats treated with $4.28 \mathrm{mg} / \mathrm{kg}$ of Mefloquine showed less population of pyramidal neurons in the pyramidal cell layer but increased population of astrocytes compared to the control group (Figure 2(d)).

\section{Discussion}

The hippocampus plays an important role in learning, memory formation, and visceral function like regulation of negative feedback of hypothalamic-pituitary axis (an endocrine function of stress response) [13]. The primary cells of the hippocampus, the pyramidal cells, constitute the circuitry for the vision guided motor function, as well as in complex object recognition in the visual processing area of the cortex [14]. 


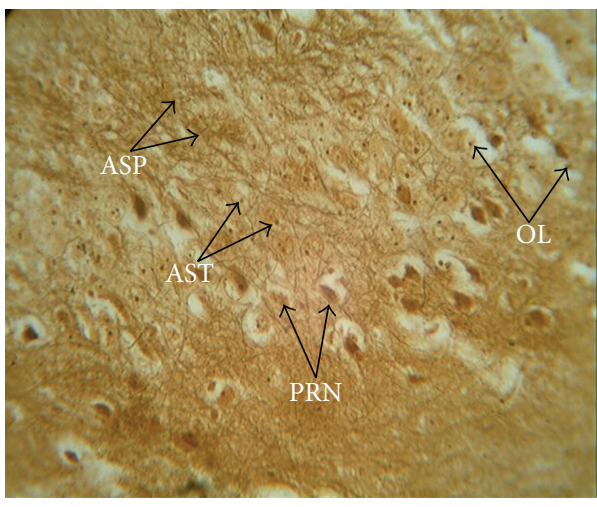

(a)

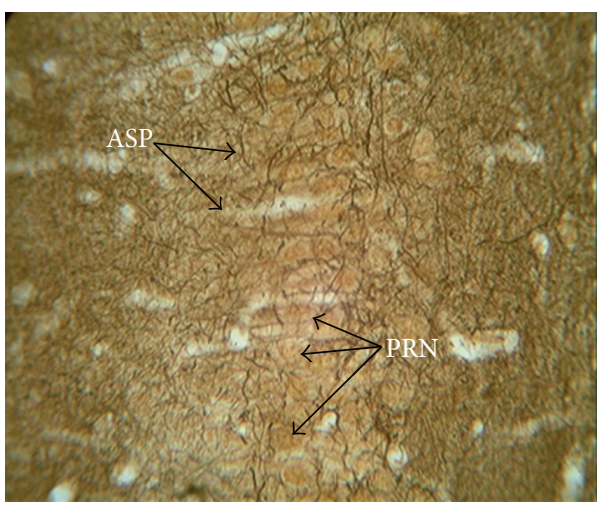

(c)

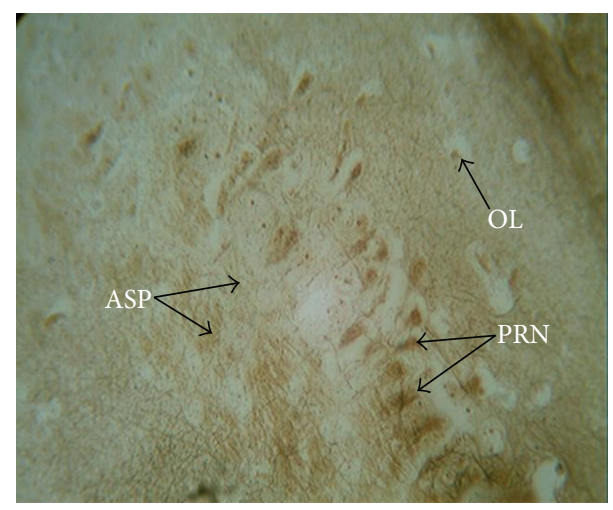

(b)

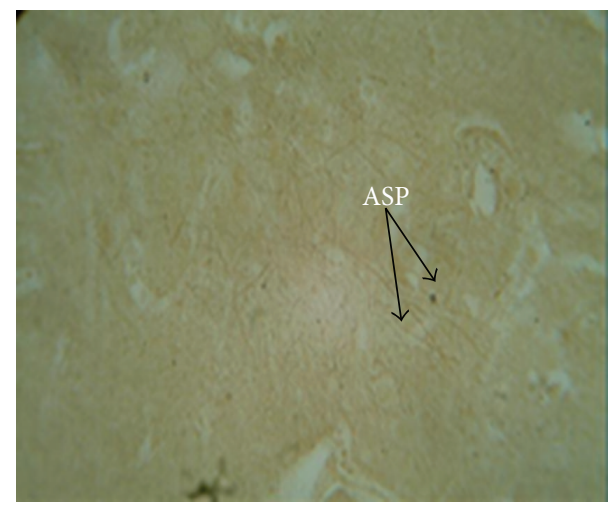

(d)

FIGURE 1: (a) Hippocampus section of control rats given distilled water, showing normal pyramidal cell neurons (PRN), astrocytes (AST), oligodendrocytes (OL), and astrocytes' processes (ASP). (b) Section of hippocampus of rats treated with 0.86/1.07 mg/kg of Artequin, showing few populations of pyramidal shaped neuron (PRN) with less visible astrocytes' processes (ASP), as well as less impregnated oligodendrocytes (OL). (c) Section of hippocampus of rats treated with $1.71 / 2.14 \mathrm{mg} / \mathrm{kg}$ of Artequin, showing mostly prominent astrocytes' processes (ASP) with less visible pyramidal neurons (PRN) and glia. (d) Section of hippocampus of rats treated with 3.42/4.28 mg/kg of Artequin, showing less visible neurons and glial astrocytes' processes (ASP) (Silver stain, Mag. $\times 400)$.

Apart from the neurons, the glia, especially the astrocytes, have special roles to play in the normal functioning of the hippocampus. They provide metabolic support for the neurons and synaptic means of communication [9], regulate limbic concentration for tight junctions and the blood-brain barrier, and serve as intermediary stations for converging nutrient gates and removal of waste products between neurons [15].

In this present study, the sections of the hippocampus of rats treated with $1.07 \mathrm{mg} / \mathrm{kg}, 2.14 \mathrm{mg} / \mathrm{kg}$, and $4.28 \mathrm{mg} / \mathrm{kg}$ per body weight of Mefloquine showed denser population of astrocytes and astrocytes' processes compared with the control group. Similar patterns of astrocyte morphology were seen in the groups treated with $0.86 / 1.07 \mathrm{mg} / \mathrm{kg}$, $1.71 / 2.14 \mathrm{mg} / \mathrm{kg}$, and $3.42 / 4.28 \mathrm{mg} / \mathrm{kg}$ per body weight of Artequin compared with the control group; these results indicate hyperplasia and hypertrophy. On the other hand, $4.28 \mathrm{mg} / \mathrm{kg}$ per body weight of Mefloquine, as well as $1.71 / 2.14 \mathrm{mg} / \mathrm{kg}$ and $3.42 / 4.28 \mathrm{mg} / \mathrm{kg}$ per body weight of Artequin, showed the presence of few or less prominent oligodendrocytes, with vacuolation. These results indicate that at the given doses supporting glia cells were affected. The present study is similar to a previous reported effect of higher dose mefloquine on brain stem nuclei [16].
Peter et al. [9] and Ekanem et al. [11] reported that, in injury of the central nervous system, astrocytes act as neuroprotective sheaths increasing in number to fill injury sites and heal and recover neurons; thus they are called reactive astrocytes. Abbas and Nelson [17] reported that the presence of reactive astrocytes is an indication of early signs of cell loss serving as an indication of pathologic process. Thus, the activities of Mefloquine and Artequin on astrocyte as seen in this present study may suggest a possible neurodegenerative potential that may be extrapolated to the entire hippocampus. This has become important because altered glial structure and function is implicated in several major mental illnesses [18].

It is reported that oligodendrocytes support axon survival and function and that their dysfunction leads to axon degeneration probably due to the lack of energy metabolites such as lactate, which it transports exclusively as monocarboxylate transporter [19]. Possible disruption of this transporter as shown in the alteration in the structure and population of oligodendrocytes in this study can produce axon damage and neuron loss in the hippocampus of rats leading to impairment in the normal functioning of the hippocampus [18]. Edgar and Sibille [18] also reported that changes in 


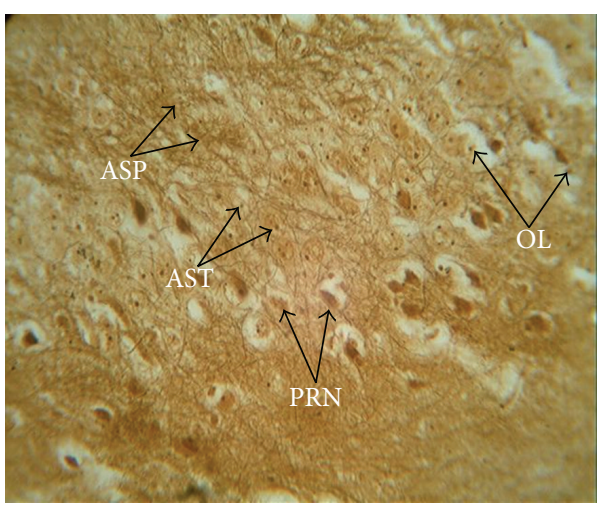

(a)

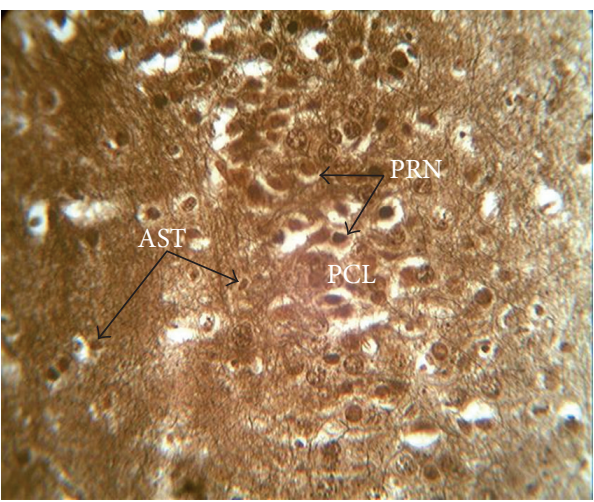

(c)

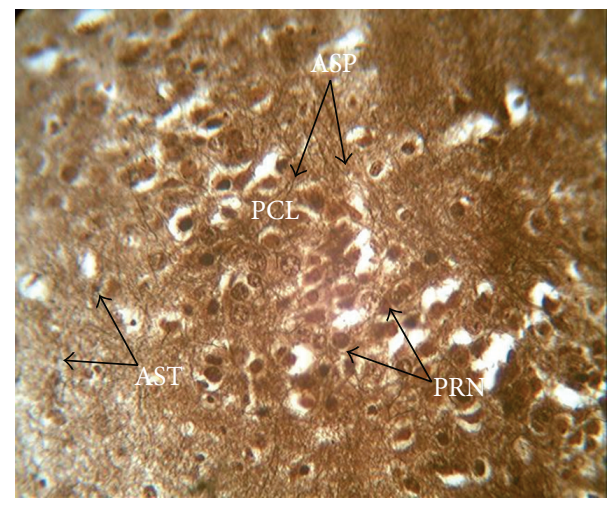

(b)

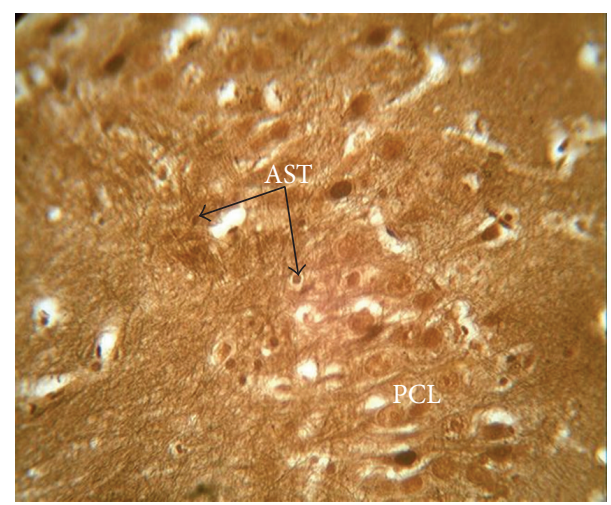

(d)

FIGURE 2: (a) Section of hippocampus of control rats showing normal pyramidal cell neurons (PRN), astrocytes (AST), astrocytes' processes (ASP), and oligodendrocytes (OL). (b) Section of hippocampus of rats treated with $1.07 \mathrm{mg} / \mathrm{kg}$ of Mefloquine, showing few populations of pyramidal neurons (PRN) in pyramidal layer with increased population of astrocytes (AST) and astrocytes' processes (ASP). (c) Section of hippocampus of rats treated with $2.14 \mathrm{mg} / \mathrm{kg}$ of Mefloquine, showing increased population of astrocytes (AST) with less population of pyramidal neurons (PRN) in the pyramidal cell layer (PCL). (d) Section of hippocampus of rats treated with $4.28 \mathrm{mg} / \mathrm{kg}$ of Mefloquine, showing less population of neurons in the pyramidal cell (PCL) layer but with increased population of astrocytes (AST) (Silver stain, Mag. $\times 400)$.

oligodendrocytes have been linked with disrupted mood regulation. The reported hippocampal activities of the two antimalarial drugs, Mefloquine and Artequin, in the present study indicate their degenerative potentials and possible psychiatry tendency that may lead to forgetfulness and seizures in the affected subject.

In conclusion, Mefloquine and Artequin induce dose dependent degenerative potentials as characterized by reactive astrocyte, astrocytes process formation in the hippocampus of rats treated with these drugs. This may impair uptake of neurotransmitter and alter neuronal environment, thus altering the hippocampus function like memory and learning. Therefore the administration and recommendation of these drugs must be with caution and on the advice of a qualified physician.

\section{Conflict of Interests}

The authors declare that they have no conflict of interests regarding the publication of this paper.

\section{Acknowledgment}

This research was carried out at the Histology Laboratory, Department of Human Anatomy, University of Uyo, Uyo, Akwa Ibom State, Nigeria.

\section{References}

[1] J. Cox-Singh, T. M. E. Davis, K. Lee et al., "Plasmodium knowlesi malaria in humans is widely distributed and potentially life threatening," Clinical Infectious Diseases, vol. 46, no. 2, pp. 165-171, 2008.

[2] World Health Organization, The Use of Antimalarial Drugs: Report of a World Health Organization Informal Consultation, World Health Organization, Geneva, Switzerland, 2000.

[3] N. J. White, F. Nosten, S. Looareesuwan et al., "Averting a malaria disaster," The Lancet, vol. 353, no. 9168, pp. 1965-1967, 1999.

[4] P. A. Winstanley, "Chemotherapy for falciparum malaria: the armoury, the problems and the prospects," Parasitology Today, vol. 16, no. 4, pp. 146-153, 2000. 
[5] N. J. White, "Delaying antimalarial drug resistance with combination chemotherapy," Parassitologia, vol. 41, no. 1-3, pp. 301308, 1999.

[6] G. Majori, "Malaria therapy in Africa with Artemisinin-based combination," Parassitologia, vol. 46, no. 1-2, pp. 85-87, 2004.

[7] T. T. Hien and N. J. White, "Qinghaosu," The Lancet, vol. 341, no. 8845, pp. 603-608, 1993.

[8] Y. Zhao, W. K. Hanton, and K.-H. Lee, "Antimalarial agents, 2. Artesunate, an inhibitor of cytochrome oxidase activity in Plasmodium berghei," Journal of Natural Products, vol. 49, no. 1, pp. 139-142, 1986.

[9] R. L. Peter, S. Eva, R. Andreas, I. H. Glenn, and B. Herbert, Glial Cells: Their Roles in Behavior, Cambridge University Press, Cambridge, UK, 1st edition, 1998.

[10] M. Wilmer, H. Maria, C. Carlas et al., "Efficacy of mefloquine and mefloquine plus artesunate combination therapy for the treatment of uncomplicated Plasmodium falciparum malaria in the Amazon basin of Peru," American Journal of Tropical Medicine and Hygiene, vol. 68, no. 1, pp. 107-110, 2003.

[11] T. B. Ekanem, E. Salami, M. B. Ekong, M. A. Eluwa, and A. O. Akpantah, "Combination therapy anti-malaria drugs, mefloquine and artequin induce reactive astrocyte formation in the hippocampus of rats," The Internet Journal of Health, vol. 9, no. 2, 2009.

[12] Y. Sano, N. Ishizaki, and Y. Ishida, "A modified BielschowskyGros'impregnation method, available to after-staining for neurosecretory material with aldehyde-fuchsin," Archivum Histologicum Japonicum, vol. 18, no. 2, pp. 263-266, 1959.

[13] R. J. Schloesser, H. K. Manji, and K. Martinowich, "Suppression of adult neurogenesis leads to an increased hypothalamopituitary-adrenal axis response," NeuroReport, vol. 20, no. 6, pp. 553-557, 2009.

[14] I. Salimi, K. M. Friel, and J. H. Martin, "Pyramidal tract stimulation restores normal corticospinal tract connections and visuomotor skill after early postnatal motor cortex activity blockade," Journal of Neuroscience, vol. 28, no. 29, pp. 74267434, 2008.

[15] J. S. George, W. A. Bernard, R. A. Wayne, K. F. Stephen, and D. U. Michael, Basic Neurochemistry: Molecular, Cellular and MEdical Aspects, (6th Ed.), Lippincott Williams and Wilkins, Philadelphia, Pa, USA, 1998.

[16] G. Dow, R. Bauman, D. Caridha et al., "Mefloquine induces dose-related neurological effects in a rat model," Antimicrobial Agents and Chemotherapy, vol. 50, no. 3, pp. 1045-1053, 2006.

[17] A. Abbas and F. K. Nelson, Robin and Cotran Pathologic Basis of Diseases, Elsevier, New Delhi, India, 7th edition, 2004.

[18] N. Edgar and E. Sibille, "A putative functional role for oligodendrocytes in mood regulation," Translational Psychiatry, vol. 2, p. e109, 2012.

[19] L. A. Cenquizca and L. W. Swanson, "Spatial organization of direct hippocampal field CA1 axonal projections to the rest of the cerebral cortex," Brain Research Reviews, vol. 56, no. 1, pp. $1-26,2007$. 

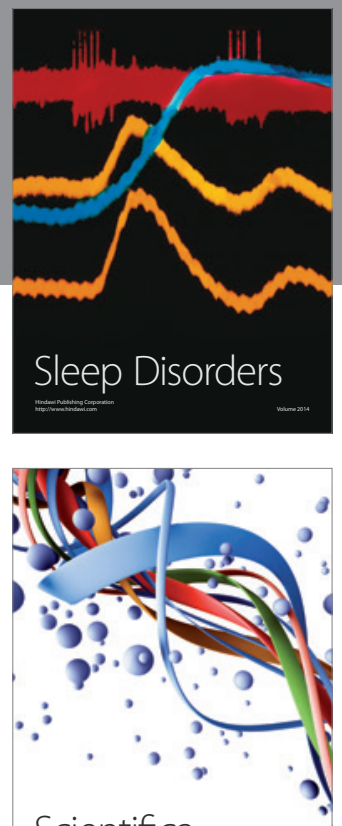

Scientifica
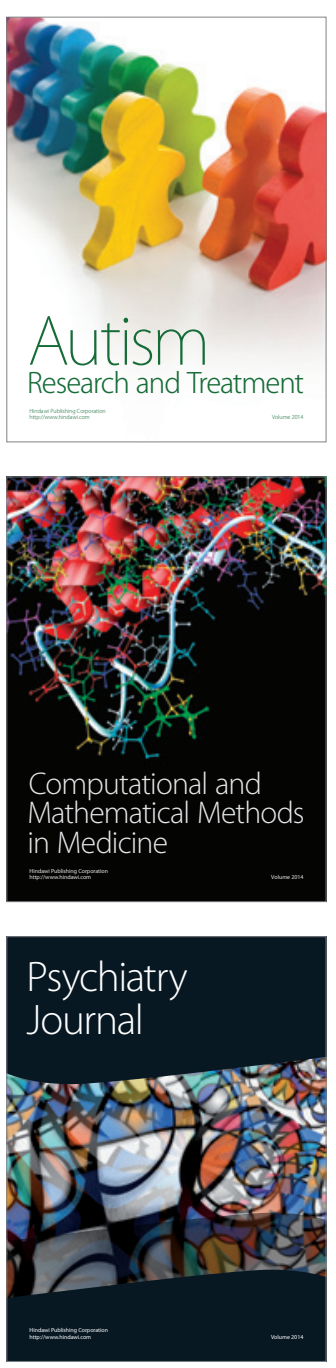
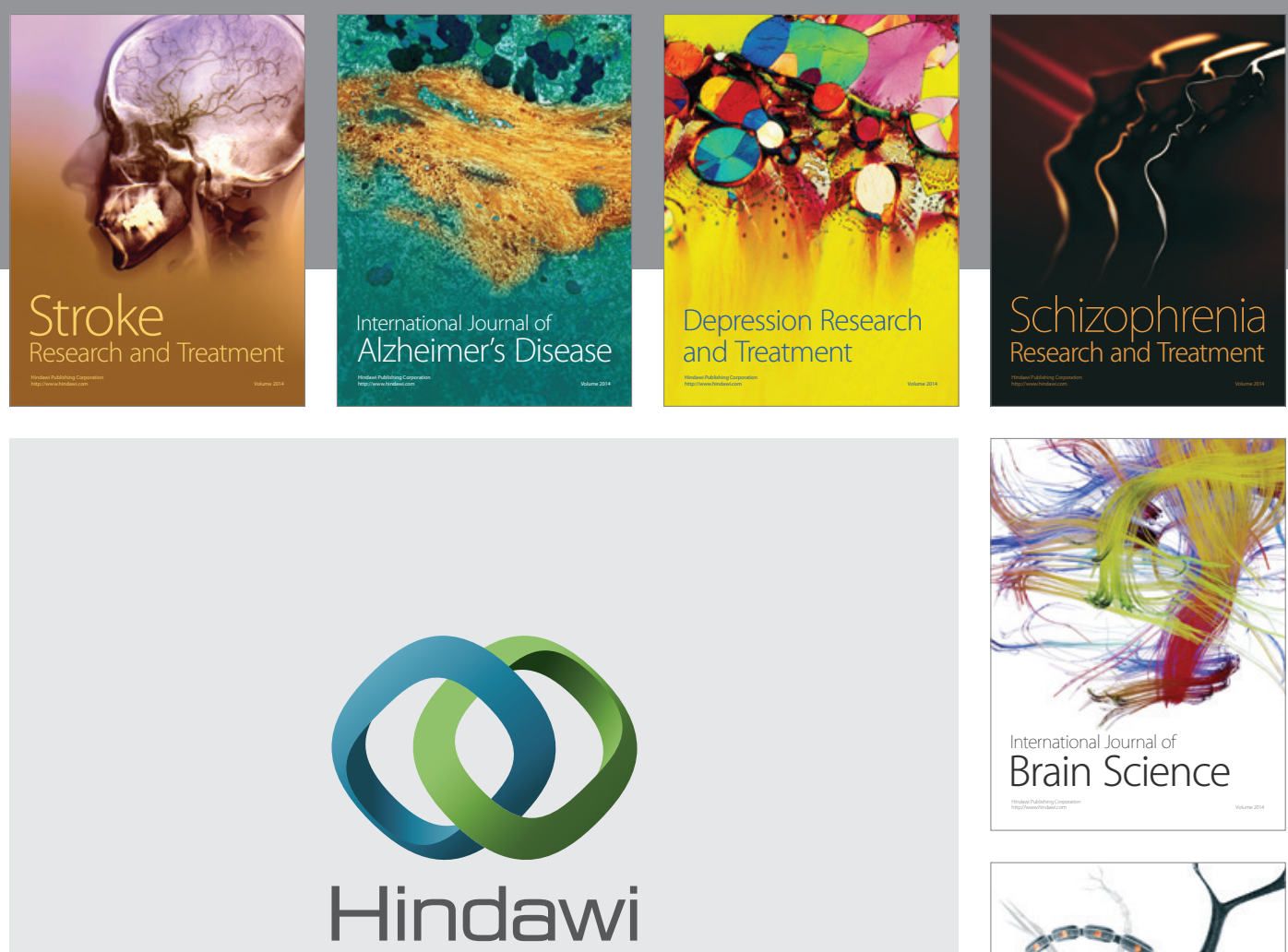

Submit your manuscripts at

http://www.hindawi.com
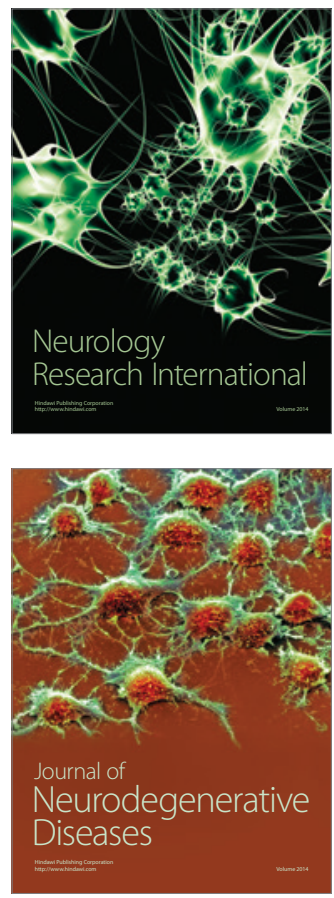

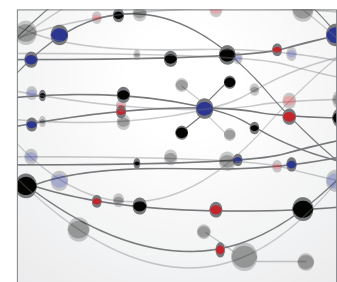

The Scientific World Journal
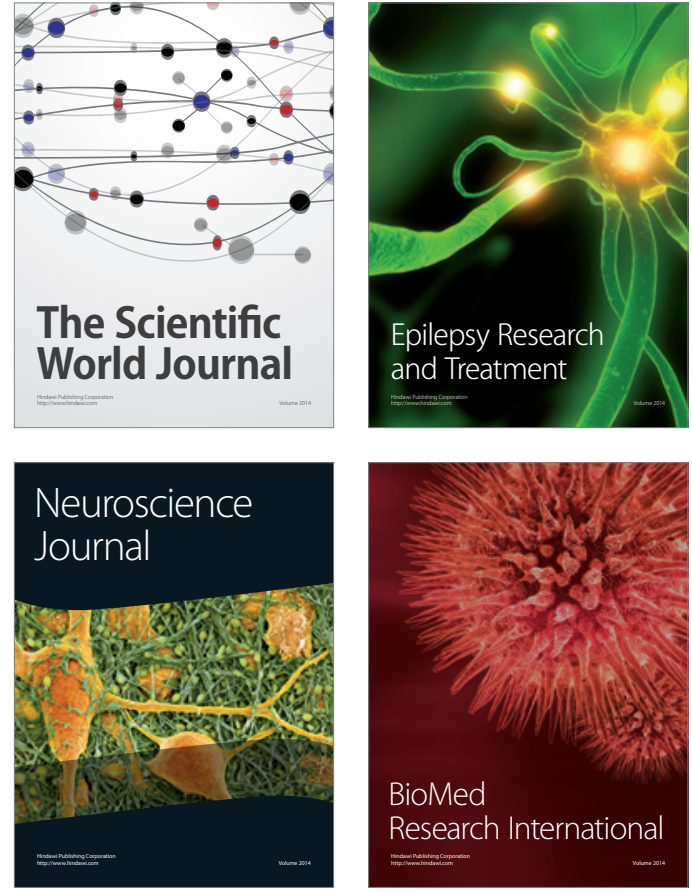

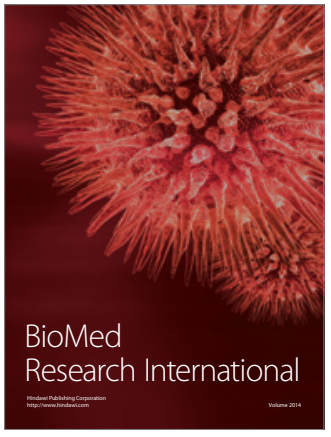

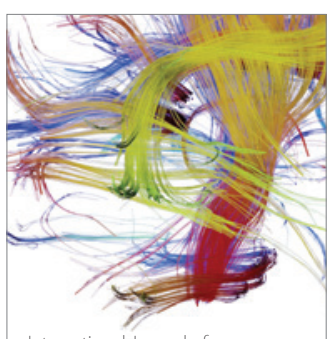

Brain Science

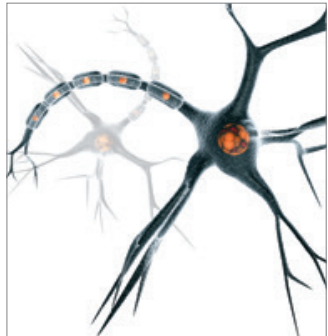

Neural Plasticity
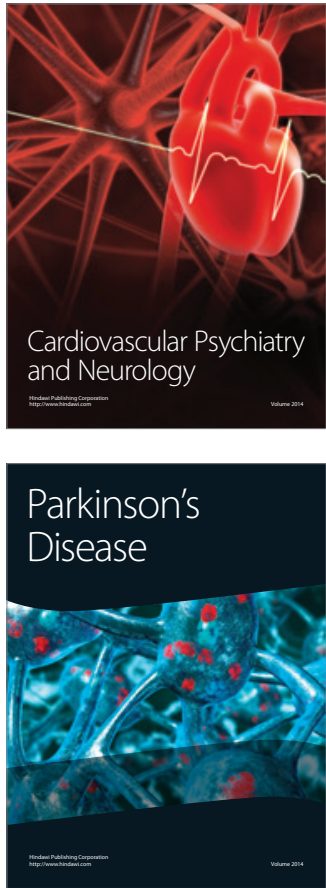